\title{
Effect of Cathodic Hydrogen Evolution on the Coercivity and Thermal Stability of Sintered NdFeB Magnets
}

\author{
Nan Haiyang, Zhu Liqun, Liu Huicong, Li Weiping
}

Beihang University, Beijing 100191, China

\begin{abstract}
The effect of cathodic hydrogen evolution on coercivity and thermal stability was investigated in sintered NdFeB magnets. The magnetic properties, phase structure and morphology were studied by SQUID-VSM, DSC, XRD, TEM and SEM. After cathodic hydrogen evolution, the $H_{\mathrm{cj}}$ decreases from $1034.8 \mathrm{kA} \cdot \mathrm{m}^{-1}$ to $963.16 \mathrm{kA} \cdot \mathrm{m}^{-1}$. The temperature coefficient $\alpha$ declines from $-0.253 \% \cdot{ }^{\circ} \mathrm{C}^{-1}$ to $-0.3229 \% \cdot{ }^{\circ} \mathrm{C}^{-1}$, and the $\beta$ declines from $-0.7518 \% \cdot{ }^{\circ} \mathrm{C}^{-1}$ to $-0.7738 \% \cdot{ }^{\circ} \mathrm{C}^{-1}$. A mechanism was proposed to explain the results. In the process of cathodic hydrogen evolution, some of the generated hydrogen atoms react with the $\mathrm{Nd}_{2} \mathrm{Fe}_{14} \mathrm{~B}$ phase and Nd-rich phase, forming $\mathrm{Nd}_{2} \mathrm{Fe}_{14} \mathrm{BH}_{x}$ and $\mathrm{NdH}_{x}$, respectively. The formation of $\mathrm{NdH}_{x}$ causes a volume expansion, which results in intergranular cracks and stress. X-ray diffraction and morphology characterization confirms the presence of these defects. These defects would significantly promote the nucleation of reverse magnetic domains, and further decline the coercivity and thermal stability of magnets.
\end{abstract}

Key words: $\mathrm{NdFeB}$; coercivity; thermal stability; hydrogen

Sintered $\mathrm{NdFeB}$ magnets are widely used in electronic industry, wind power generation and electric vehicle, due to their excellent magnetic properties ${ }^{[1,2]}$. The magnets have poor corrosion resistance ${ }^{[3,4]}$. Surface treatment is necessary to improve the corrosion resistance. Electroplating $\mathrm{Ni}, \mathrm{Zn}$ and $\mathrm{Ni} / \mathrm{Cu} / \mathrm{Ni}$ coatings or electrophoresis of epoxy coating are the most commonly used surface treatments in industry $^{[5,6]}$. However, it has been noticed that these surface treatments declined the magnetic properties ${ }^{[7-11]}$. In the electroplating or electrophoresis processes, cathodic hydrogen evolution is the main side reaction and inevitable, while the composition, microstructure and magnetic properties of $\mathrm{NdFeB}$ magnets are sensitive and vulnerable to hydrogen. It is reasonable to relate the declined magnetic properties with cathodic hydrogen evolution. Coercivity and thermal stability are important magnetic properties for the application of magnets, especially at high temperature. So it is very significant to clarify how cathodic hydrogen evolution affects the coercivity and thermal stability.

The magnets are composed of matrix $\mathrm{Nd}_{2} \mathrm{Fe}_{14} \mathrm{~B}$ phase and intergranular Nd-rich phase. The coercivity and thermal stability are in close relation with the composition and microstructure of magnets. Additions including $\mathrm{Ce}^{[12]}$, $\mathrm{Ho}_{63.4} \mathrm{Fe}_{36.6}{ }^{[13]}, \mathrm{DyH}_{x}{ }^{[14]}, \mathrm{Y}_{72} \mathrm{Co}_{28}{ }^{[15]}, \mathrm{Dy}_{82.3} \mathrm{Co}_{17.7}{ }^{[16]}$ and $\mathrm{Zr}^{[17]}$ etc. were used to enhance the coercivity and thermal stability by composition and microstructure optimization. While the local stress near the grain boundary ${ }^{[18]}$, cracks in the magnets ${ }^{[19]}$ and lattice misfit of $\mathrm{N}$-rich phase with $\mathrm{Nd}_{2} \mathrm{Fe}_{14} \mathrm{~B}$ phase $^{[20]}$ all could decline the coercivity. Thus, identifying the relations among cathodic hydrogen evolution, composition and microstructure is particularly important.

In the present study, we investigated how cathodic hydrogen evolution declined the coercivity and thermal stability. A mechanism was proposed to explain this phenomenon. This knowledge would also provide a chance to avoid the coercivity and thermal stability decline or regain them.

\section{Experiment}

The commercial sintered $\mathrm{NdFeB}$ magnets $\left(\mathrm{Nd}_{15.1} \mathrm{~Tb}_{0.6} \mathrm{Fe}_{77.4} \mathrm{~B}_{6.9}\right)$ were used in the investigation. Magnets were polished with $\mathrm{SiC}$ abrasive papers (of grades in the range of 600 2000), ultrasonically cleaned in alcohol and 
then dried in air. The cathodic hydrogen evolution was performed in $3.5 \mathrm{wt} \% \mathrm{NaCl}$ solution with a DC power supply (KAE-1201) at room temperature. The $3.5 \mathrm{wt} \% \mathrm{NaCl}$ solution was used to simulate the aqueous salt solution in electroplating and electrophoresis. Magnets and Pt plate were used as cathode and anode, respectively. Hydrogen was generated at the $\mathrm{NdFeB}$ magnets surface with cathodic current density of $0.2,0.5$ and $1 \mathrm{~A} / \mathrm{dm}^{2}$ for $30 \mathrm{~min}$. In actual electroplating or electrophoresis process, the cathodic current density usually varied from a few tenths of amperes per square decimeter to several amperes per square decimeter. The cathodic current density was also bigger in the edges and corners of cathode due to tip effect. The deposition time varied from tens of minutes to hours. So these cathodic current density and time were chosen in the experiment. The electrode reaction was as following ${ }^{[21]}$ :

Anode reaction: $4 \mathrm{OH}^{-} \rightarrow \mathrm{O}_{2}+2 \mathrm{H}_{2} \mathrm{O}+4 \mathrm{e}$

Cathode reaction: $\mathrm{H}^{-}+\mathrm{e}^{-} \rightarrow \mathrm{H}$

Magnetic properties were measured using an SQUID-VSM magnetic measurement device with a maximum magnetic field of $7 \mathrm{~T}$ at 300 and $373 \mathrm{~K}$. The Curie temperature was tested by differential scanning calorimetry (DSC, NETZSCH) at a heating rate of $10{ }^{\circ} \mathrm{C} / \mathrm{min}$. Phase analysis was examined by X-ray diffraction (XRD, Rigaku, Japan) with $\mathrm{Cu} \mathrm{K \alpha}$ radiation. Transmission electron microscopy was carried out by FEI Tecnai G2 F20 operated at $200 \mathrm{kV}$. The surface morphologies were characterized by field emission scanning electron microscopy (FESEM, Apollo 300).

\section{Results and Discussion}

Fig.1 shows the remanence $\left(B_{\mathrm{r}}\right)$, coercivity $\left(H_{\mathrm{cj}}\right)$ and maximum energy product $\left((B H)_{\max }\right)$ of the original and treated $\mathrm{NdFeB}$ magnets. The $H_{\mathrm{cj}}$ declines obviously after cathodic hydrogen evolution. It declines from 1034.8 to $963.16 \mathrm{kA} \cdot \mathrm{m}^{-1}$ at $300 \mathrm{~K}$, and from $469.64 \mathrm{kA} \cdot \mathrm{m}^{-1}$ to 421.88 $\mathrm{kA} \cdot \mathrm{m}^{-1}$ at $373 \mathrm{~K}$. The $B_{\mathrm{r}}$ and $(B H)_{\max }$ also declines significantly. However, when the cathodic current density increases to $1 \mathrm{~A} / \mathrm{dm}^{2}$, the magnetic properties recover partly. This might be due to the shedding of the most hydrogenated surface grains, which would be discussed later.

Fig. 2 shows the differential scanning calorimetry (DSC) curves of the original and treated $\mathrm{NdFeB}$ magnets. It indicates the Curie temperature $\left(T_{\mathrm{C}}\right)$ is affected by cathodic hydrogen evolution. The $T_{\mathrm{C}}$ increases by about $2{ }^{\circ} \mathrm{C}$ from the original $310^{\circ} \mathrm{C}$ after cathodic hydrogen evolution. The increased $T_{\mathrm{C}}$ results from the volume expansion, which is induced by hydrogen entering crystal lattice of magnets ${ }^{[22]}$.
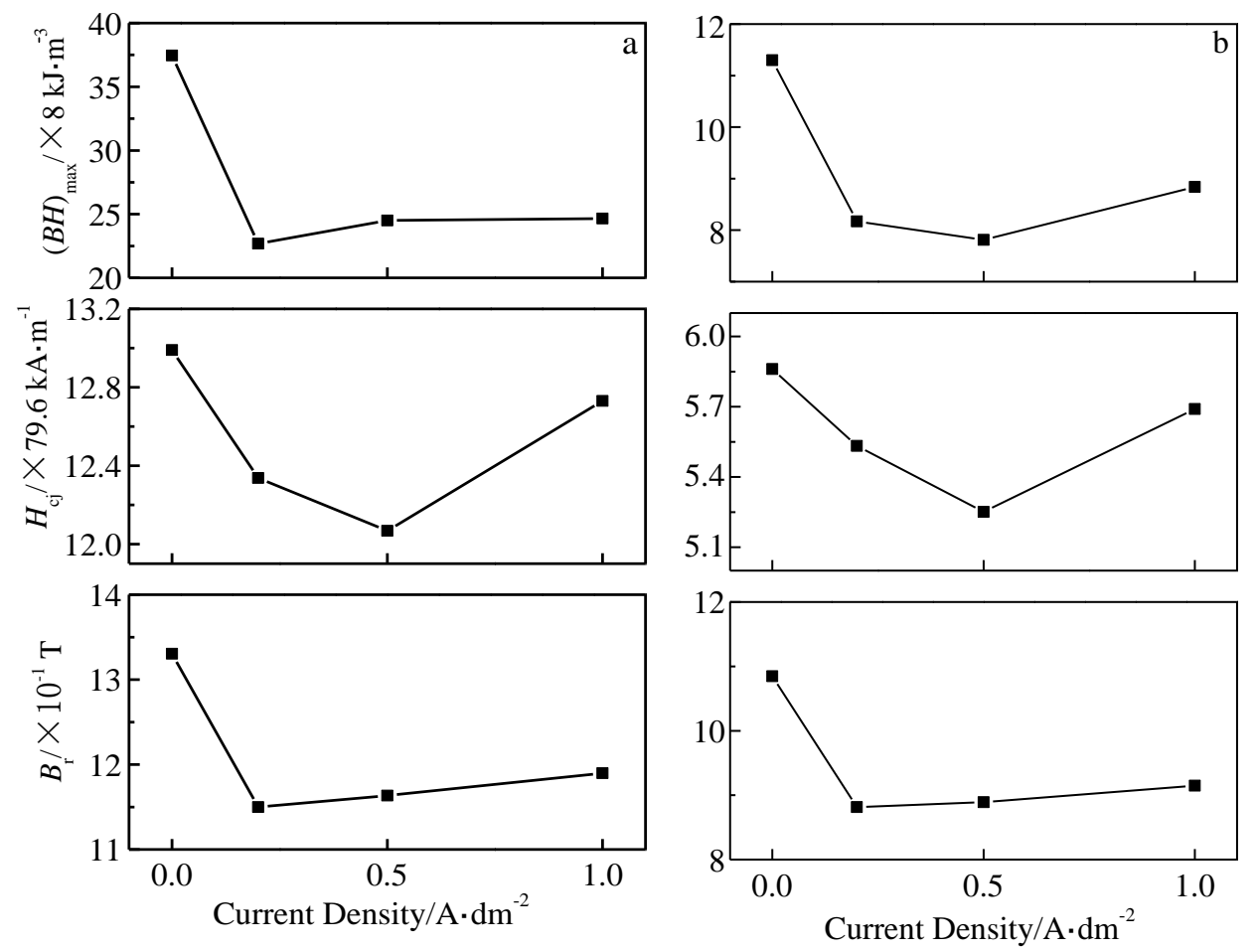

Fig.1 Remanence $\left(B_{\mathrm{r}}\right)$, coercivity $\left(H_{\mathrm{cj}}\right)$ and maximum energy product $\left((B H)_{\max }\right)$ of NdFeB magnets treated by cathodic hydrogen evolution with different current density for 30 min tested at $300 \mathrm{~K}$ (a) and $373 \mathrm{~K}$ (b) 


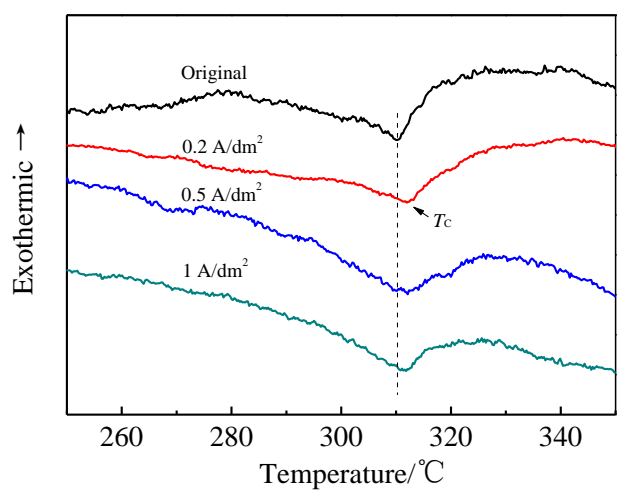

Fig.2 DSC curves of original and treated NdFeB magnets by cathodic hydrogen evolution for $30 \mathrm{~min}$

The temperature coefficients of $B_{\mathrm{r}}(\alpha)$ and $H_{\mathrm{cj}}(\beta)$ of magnets from $300 \mathrm{~K}$ to $373 \mathrm{~K}$ are shown in Fig.3. They reflect the thermal stability of magnets, which are calculated from the following formulas:

$$
\begin{aligned}
& \alpha=\frac{B_{\mathrm{rT}}-B_{\mathrm{rT}_{0}}}{B_{\mathrm{rT}_{0}}\left(T-T_{0}\right)} \times 100 \% \\
& \beta=\frac{H_{\mathrm{T}}-H_{\mathrm{T}_{0}}}{H_{\mathrm{T}_{0}}\left(T-T_{0}\right)} \times 100 \%
\end{aligned}
$$

where $\alpha$ and $\beta$ are the temperature coefficients of $B_{\mathrm{r}}(\alpha)$ and $H_{\text {cj }}(\beta)$ at temperature range from $T_{0}$ to $T$, respectively. The $\alpha$ declines from $-0.253 \% \cdot{ }^{\circ} \mathrm{C}^{-1}$ to $-0.3229 \% \cdot{ }^{\circ} \mathrm{C}^{-1}$, and the $\beta$ declines from $-0.7518 \% \cdot{ }^{\circ} \mathrm{C}^{-1}$ to $-0.7738 \% \cdot{ }^{\circ} \mathrm{C}^{-1}$ after cathodic hydrogen evolution. It is shown the cathodic hydrogen evolution reduces the thermal stability of magnets.

The coercivity and thermal stability are in close relation with the composition and microstructure of magnets. To investigate the effect of cathodic hydrogen evolution on the composition and microstructure of magnets, XRD, TEM and SEM were employed in the study. The diffraction patterns of the original and treated $\mathrm{NdFeB}$ magnets are shown in Fig.4. The diffraction peaks are characteristic peaks of $\mathrm{Nd}_{2} \mathrm{Fe}_{14} \mathrm{~B}$ phase (PDF 36-1296) and Nd-rich phase (PDF 07-0090) ${ }^{[23]}$. No new diffraction peaks appear in the patterns of treated magnets. However, all the diffraction peaks shift relatively toward smaller diffraction angles. This reveals that cathodic hydrogen evolution expands the lattice parameters of the $\mathrm{Nd}_{2} \mathrm{Fe}_{14} \mathrm{~B}$ phase and Nd-rich phase. It is due to that parts of the generated hydrogen atoms react with the $\mathrm{Nd}_{2} \mathrm{Fe}_{14} \mathrm{~B}$ phase and Nd-rich phase, forming $\mathrm{Nd}_{2} \mathrm{Fe}_{14} \mathrm{BH}_{x}$ and $\mathrm{NdH}_{x}$, respectively $^{[24,25]}$. The reaction is as following ${ }^{[21,26]}$ :

$\mathrm{Nd}+x \mathrm{H} \rightarrow \mathrm{NdH} x$

$\mathrm{Nd}_{2} \mathrm{Fe}_{14} \mathrm{~B}+x \mathrm{H} \rightarrow \mathrm{Nd}_{2} \mathrm{Fe}_{14} \mathrm{BH}_{x}$

TEM images of the original and treated $\mathrm{NdFeB}$ magnets

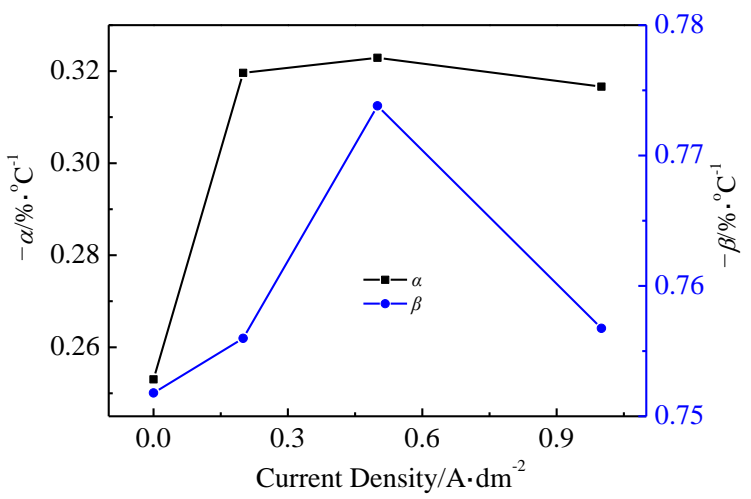

Fig.3 Temperature coefficients (from $300 \mathrm{~K}$ to $373 \mathrm{~K}$ ) of remanence $(\alpha)$ and coercivity $(\beta)$ of the $\mathrm{NdFeB}$ magnets treated by cathodic hydrogen evolution for $30 \mathrm{~min}$

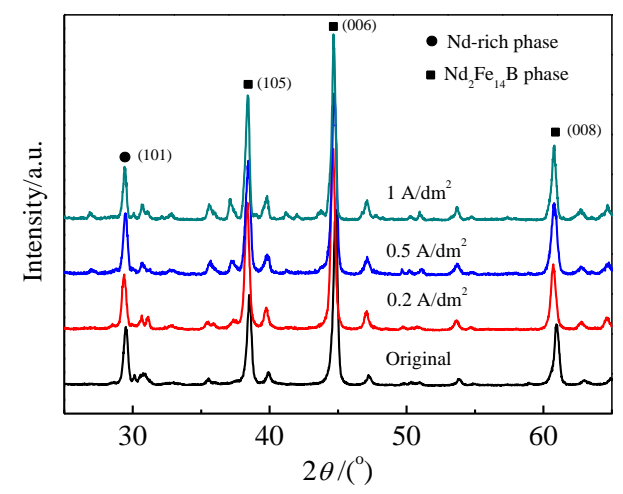

Fig.4 XRD patterns of original and treated $\mathrm{NdFeB}$ magnets by cathodic hydrogen evolution for $30 \mathrm{~min}$

are shown in Fig.5. The results of FETEM test are consistent with that of XRD. As shown in the images and SAED pattern, the crystal structure of tetragonal $\mathrm{Nd}_{2} \mathrm{Fe}_{14} \mathrm{~B}$ phase and hexagonal close packed (hcp) Nd-rich phase do not change after cathodic hydrogen evolution. Limited by accuracy, the expansion of lattice parameters could not be discerned directly in the image.

The surface morphologies of the original and treated NdFeB magnets are shown in Fig.6. The original magnets are compact. After $0.2 \mathrm{~A} / \mathrm{dm}^{2}$ cathodic hydrogen evolution for 30 min, some intergranular cracks and bulged matrix grains appear, as shown in Fig.6a and 6 b.

It is due to the absorption of hydrogen by the $\mathrm{Nd}_{2} \mathrm{Fe}_{14} \mathrm{~B}$ phase and Nd-rich phase, as mentioned in the XRD analysis. The formation of $\mathrm{NdH}_{x}$ causes a volume expansion of the grain boundary ${ }^{[27,28]}$, which results in intergranular cracks and stress. With the adding of current density, the volume 

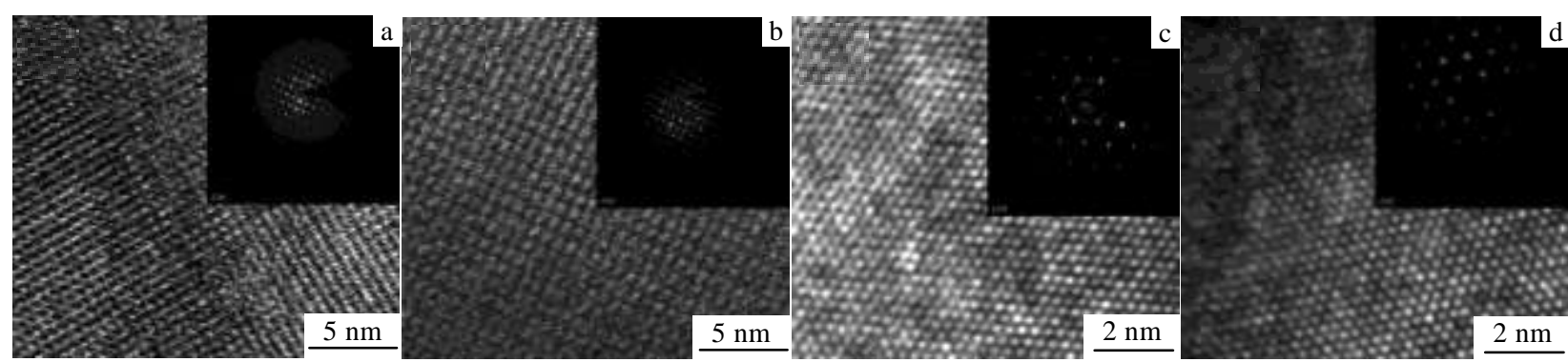

Fig.5 TEM images and selected area electron diffraction patterns of original $\mathrm{NdFeB}$ magnets $(\mathrm{a}, \mathrm{c})$ and the magnets treated by cathodic hydrogen evolution with $0.5 \mathrm{~A} / \mathrm{dm}^{2}$ for $30 \mathrm{~min}$ (b, d): (a, b) $\mathrm{Nd}_{2} \mathrm{Fe}_{14} \mathrm{~B}$ phase and (c, d) Nd-rich phase

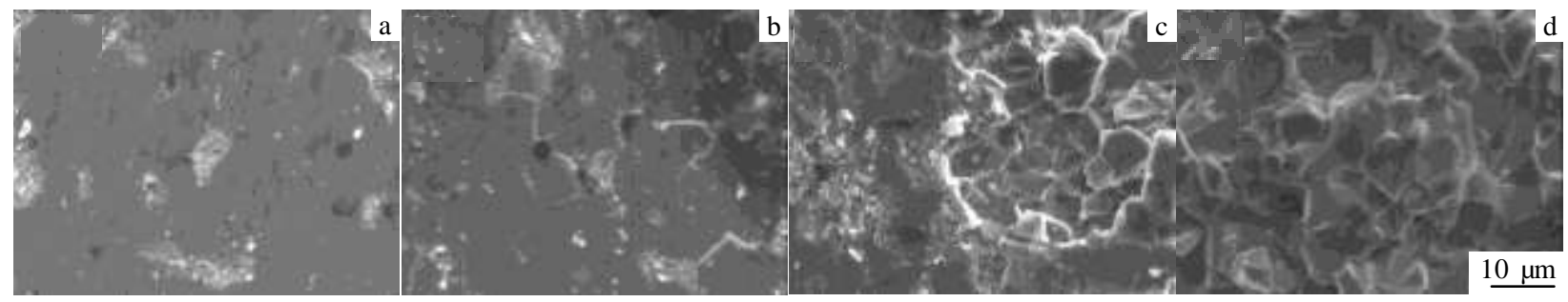

Fig.6 Surface morphologies of original $\mathrm{NdFeB}$ magnets (a) and the magnets treated by cathodic hydrogen evolution for $30 \mathrm{~min}$ : (b) $0.2 \mathrm{~A} / \mathrm{dm}^{2}$, (c) $0.5 \mathrm{~A} / \mathrm{dm}^{2}$, and (d) $1 \mathrm{~A} / \mathrm{dm}^{2}$

expansion also increases. Parts of grains shred from magnets surface after $0.5 \mathrm{~A} / \mathrm{dm}^{2}$ cathodic hydrogen evolution. And almost all surface grains shred after $1 \mathrm{~A} / \mathrm{dm}^{2}$ cathodic hydrogen evolution. The intergranular cracks are obvious in the images. The shedding of the most hydrogenated surface grains might partly recover the declined magnetic properties, as mentioned previously.

Cathodic hydrogen evolution induces some changes of composition and microstructure in the magnets, including the interstitial hydrogen, intergranular cracks and stress. These changes would promote the nucleation of reverse magnetic domains, which further declines the coercivity and thermal stability of the magnets. In $\mathrm{NdFeB}$ magnets, the coercivity is determined by the activation energy of reverse magnetic domains nucleation. The phenomenological equation is used ${ }^{[19]}$ :

$$
H_{\mathrm{cj}}=a H_{\mathrm{a}}-N_{\mathrm{eff}} M_{\mathrm{s}}
$$

where $H_{\mathrm{a}}$ is the anisotropy field, $a$ is structure factor, $M_{\mathrm{s}}$ is the spontaneous magnetization, and $N_{\text {eff }}$ is the effective demagnetization factor. The interstitial hydrogen would decrease $H_{\mathrm{a}}{ }^{[22]}$. And the intergranular cracks and stress would increase the $N_{\text {eff }}^{[19]}$. These situations all lead to declined coercivity. At a relatively high temperature, the treated magnets would be more prone to nucleate reverse magnetic domains, which also decreases the thermal stability. To avoid the coercivity and thermal stability of magnets declining, suppressing the cathodic hydrogen evolution in surface treatments should receive more attention.

\section{Conclusions}

1) Cathodic hydrogen evolution results in declined coercivity and thermal stability of sintered $\mathrm{NdFeB}$ magnets. The $H_{\mathrm{cj}}$ decreases from $1034.8 \mathrm{kA} \cdot \mathrm{m}^{-1}$ to $963.16 \mathrm{kA} \cdot \mathrm{m}^{-1}$ at $300 \mathrm{~K}$. The $\alpha$ declines from $-0.253 \% \cdot{ }^{\circ} \mathrm{C}^{-1}$ to $-0.3229 \% \cdot{ }^{\circ} \mathrm{C}^{-1}$, and the $\beta$ declines from $-0.7518 \% \cdot{ }^{\circ} \mathrm{C}^{-1}$ to $-0.7738 \% \cdot{ }^{\circ} \mathrm{C}^{-1}$. The $B_{\mathrm{r}}$ and $(B H)_{\max }$ also drops significantly.

2) Cathodic hydrogen evolution expands the lattice parameters of the $\mathrm{Nd}_{2} \mathrm{Fe}_{14} \mathrm{~B}$ phase and Nd-rich phase, and forms $\mathrm{Nd}_{2} \mathrm{Fe}_{14} \mathrm{BH}_{x}$ and $\mathrm{NdH}_{x}$. The formation of $\mathrm{NdH}_{x}$ causes a volume expansion of the grain boundary, which results in intergranular cracks and stress.

3) The interstitial hydrogen, intergranular cracks and stress would promote the nucleation of reverse magnetic domains, which further decreases the coercivity and thermal stability of magnets.

\section{References}

1 Zhang Y J, Ma T Y, Liu X L et al. Journal of Magnetism and Magnetic Materials[J], 2016, 399: 159

2 Wang X L, Zhao L N, Ding K H et al. Chinese Physics $B[\mathrm{~J}]$, 2015, 24(3): 358

3 Isotahdon E, Huttunen-Saarivirta E, Heinonen S et al. Journal of Alloys and Compounds[J], 2015, 626: 349 
4 Zhang X, Ma Y T, Zhang B et al. Corrosion Science[J], 2014, 87: 156

5 Yang H X, Mao S D, Song Z G. Rare Metal Materials and Engineering[J], 2011, 40(12): 2241 (in Chinese)

6 Li B, Wang C B, Wang X D et al. Rare Metal Materials and Engineering[J], 2015, 44(1): 174 (in Chinese)

7 Cheng Y Y, Pang X L, Gao K W et al. Thin Solid Films[J], 2014, 550: 428

8 Li J L, Wang Y X, Wang L P. Thin Solid Films[J], 2014, 568: 87

9 Mao S D, Xie T T, Zheng B Z et al. Surface \& Coatings Technology[J], 2012, 207: 149

10 Xie T T, Mao S D, Yu C et al. Vacuum[J], 2012, 86(10): 1583

11 Cheng C W, Man H C, Cheng F T. IEEE Transactions on Magnetics[J], 1997, 33(5): 3910

12 Pei K, Zhang X, Lin M et al. Journal of Magnetism and Magnetic Materials[J], 2016, 398: 96

13 Liang L P, Ma T Y, Wu C et al. Journal of Magnetism and Magnetic Materials[J], 2016, 397: 139

14 Ma T Y, Wang X J, Liu X L et al. Journal of Physics D: Applied Physics[J], 2015, 48(21): 215001

15 Ding G F, Guo S, Cai L W et al. IEEE Transactions on Magnetics[J], 2015, 51(8): 2100504

16 Zhang X F, Guo S, Yan C J et al. Journal of Applied Physics[J], 2014, 115(17): 17A757
17 Liu Z W, Qian D Y, Zhao L Z et al. Journal of Alloys and Compounds[J], 2014, 606: 44

18 Liu Q Z, Xu F, Wang J et al. Scripta Materialia[J], 2013, 68(9): 687

19 Akiya T, Sasaki T T, Ohkubo T et al. Journal of Magnetism and Magnetic Materials[J], 2013, 342: 4

20 Kim T H, Lee S R, Namkumg S et al. Journal of Alloys and Compounds[J], 2012, 537: 261

21 Yang H, Mao S, Song Z. Materials and Corrosion[J], 2012, 63(4): 292

22 Chang H, Zhang X D, Yang Y C. Solid State Communications[J], 2001, 119(6): 403

23 Mao S D, Yang H X, Song Z L et al. Corrosion Science[J], 2011, 53(5): 1887

24 Guo S, Zhou Q Y, Chen R J et al. Journal of Applied Physics[J], 2011, 109(7): 07A734

25 Tan C L, Bai S X, Zhang H et al. Journal of Alloys and Compounds[J], 2004, 368(1-2): 333

26 Guo S, Liu Y H, Chen B C et al. Journal of Applied Physics[J], 2012, 111(7): 07A740

27 Kim A S, Camp F E, Lizzi T. Journal of Applied Physics[J], 1996, 79(8): 4840

28 Li J J, Li A H, Zhu M G et al. Journal of Applied Physics[J], 2011, 109(7): 07A744

\title{
阴极析氢对钕铁嗍磁体矫顽力和热稳定性的影响
}

\author{
南海洋, 朱立群, 刘慧丛, 李卫平 \\ (北京航空航天大学, 北京 100191)
}

\begin{abstract}
摘 要: 研究了由阴极析氢导致的烧结钕铁硼磁体矫顽力和热稳定性下降。使用SQUID-VSM、DSC、XRD、TEM和SEM系统地研究了 磁性能, 相结构和形貌的变化。阴极析氢后, $300 \mathrm{~K}$ 时矫顽力从 $1034.8 \mathrm{kA} \cdot \mathrm{m}^{-1}$ 下降到 $963.16 \mathrm{kA} \cdot \mathrm{m}^{-1}$ 。温度系数 $\alpha$ 从 $-0.253 \% \cdot{ }^{\circ} \mathrm{C}^{-1}$ 下降到 $-0.3229 \% \cdot{ }^{\circ} \mathrm{C}^{-1}, \beta$ 从 $-0.7518 \% \cdot{ }^{\circ} \mathrm{C}^{-1}$ 下降到 $-0.7738 \% \cdot{ }^{\circ} \mathrm{C}^{-1}$ 。其作用机制如下: 在阴极析氢过程中, 部分产生的氢与 $\mathrm{Nd}_{2} \mathrm{Fe}_{14} \mathrm{~B}$ 相和富钕相反 应, 相应地生成 $\mathrm{Nd}_{2} \mathrm{Fe}_{14} \mathrm{BH}_{x}$ 和 $\mathrm{NdH}_{x}$ 。生成的 $\mathrm{NdH}_{x}$ 会体积膨胀, 导致了晶间裂纹和应力。XRD和微观形貌都确认了这些缺陷的存在。这 些缺陷促进了反磁化畴的形核, 进而降低了磁体的矫顽力和热稳定性。
\end{abstract}

关键词: 钕铁硼; 矫顽力; 热稳定性; 氢

作者简介: 南海洋, 男, 1986 年生, 博士生, 北京航空航天大学材料科学与工程学院, 北京 100191, 电话: 010-82317113, E-mail: nanhy@buaa.edu.cn 